\title{
O Direito à Saúde na Constituição angolana e brasileira: um estudo comparado
}

The Right to Health in the Angolan and Brazilian Constitution: a comparative study

El derecho a la salud en la Constitución de Angola y de Brasil: un estudio comparativo

Izamba Kapalu ${ }^{1}$

RESUMO. Introdução: Trata o artigo de um estudo comparado entre a Constituição da República Federativa do Brasil de 1988 e a Constituição da República de Angola especialmente no que se refere ao Direito à Saúde e aos aspectos a ele relacionados. Metodologia: para a análise do texto normativo utilizou-se da análise do discurso a fim de comparar as duas cartas políticas em seus aspectos referentes à saúde. Resultados: resultou em constatar um grande avanço da Constituição angolana que, inspirada na CF-88 garantiu alguns direitos aos cidadãos angolanos no que se refere à saúde, mas não tornou um direito como ocorre com a carta brasileira. Conclusão: concluiu-se que, há um grande avanço e conquistas cidadãs na Constituição angolana mas a Constituição brasileira é mais abrangente e positiva na garantia de direitos relativos à saúde.

Palavras-chave: Constituição. Brasil. Angola. Estudo comparado.

ABSTRACT. Introduction: This article of a comparative study between the Constitution of the Federative Republic of Brazil in 1988 and the Constitution of the Republic of Angola in particular as regards the right to health and issues related to it. Methodology: for the analysis of the legal text was used discourse analysis to compare the two political cards in their health-related aspects. Results: resulted in a major breakthrough note of the Angolan Constitution, inspired by the CF-88 has secured certain rights to Angolan citizens with regard to health, but has a right as with the Brazilian letter. Conclusion: it was concluded that there is a major breakthrough and civic achievements in the Angolan Constitution but the Brazilian Constitution is more comprehensive and positive in ensuring rights to health.

Keywords: Constitution. Brazil. Angola. Comparative study.

RESUMEN. Introducción: en este artículo de un estudio comparativo entre la Constitución de la República Federativa del Brasil en 1988 y la Constitución de la República de Angola en particular en lo que se refiere al derecho a la salud y los problemas relacionados con ella. Metodología: para el análisis del texto legal se utilizó el análisis del discurso para comparar las dos cartas políticas en sus aspectos

\footnotetext{
${ }^{1}$ Mestre em Gerontologia pela Universidade Católica de Brasília - UCB (2015), pesquisador do Ministério de Saúde da República de Angola, Moxico, Lumbala N'guimbo. izambakapalu@sapo.pt
} 
relacionados con la salud. Resultados: dado lugar a un gran avance nota de la Constitución de Angola, inspirado por el CF-88 se ha asegurado ciertos derechos a los ciudadanos de Angola en materia de salud, pero tiene un derecho como con la letra de Brasil. Conclusión: se concluyó que existe un gran avance y logros cívicos en la Constitución de Angola, pero la Constitución de Brasil es más amplio y positivo para garantizar los derechos a la salud.

Palabras clave: Constitución. Brasil. Angola. Estudio comparativo

\section{Introdução}

Uma Constituição é um contrato entre o Estado e a sociedade. Uma Constituição é tanto Constituição política quanto Constituição social, é o documento que ordena a vida estatal ela envolve a problemática do estado em geral bem como o estado como comunidade política. Regula a cidadania, o poder político e as funções, órgãos e atos do estado.

A Constituição brasileira de 1988 (1) foi promulgada em 5 de outubro de 1988, após a reunião em Assembleia constituinte, em que representantes eleitos, com apoio da sociedade brasileira, escreveu a nova Carta Política para o país.

Conhecida como a constituição cidadã, elegeu os direitos fundamentais como o paradigma a inspirar seu texto, bem como todo o arcabouço jurídico brasileiro.

A Constituição da República de Angola (2) foi promulgada em de janeiro 2010, após eleições parlamentares livres em setembro de 2008.

Para a Organização Mundial da Saúde, o conceito de saúde é o completo bemestar físico, mental e social. Combinado o conceito de saúde com as regras constitucionais, tem-se a proteção da saúde pela Carta de Direitos máxima dos países.

Mas para se chegar a essas conquistas um longo caminho a humanidade teve que percorrer. A dignidade do Ser Humano é preocupação desde o início da sociedade. Um fato paradigmático que aconteceu na história foi a Declaração Universal que representou um sistema de impulso fundamental da conduta humana. Foi livre e claramente aceito, através dos governos e pelo grupo preponderante dos homens que vive no planeta Terra.

O homem sempre teve a necessidade de abrigo e de saúde do mesmo modo que as diversas gerações sempre lutaram pelos mas básicos direitos da pessoa humana. 
Após movimentos, lutas e revoluções os direitos e liberdade individuas passaram a constituir um ideal a ser alcançado por todos e as cartas políticas das nações passaram a ser repositório máximo dessas garantias fundamentais.

Nas constituições duas vertentes do mesmo direito são asseguradas integralmente: os direitos humanos individuais, aqueles que protegem o indivíduo contra possíveis arbitrariedades do estado e garantem o direito à vida, à segurança, à igualdade de tratamento perante a lei, à liberdade, ao voto e à elegibilidade e os direitos humanos sociais que são direitos dos indivíduos e grupos de indivíduos que devem ser assegurados pelo estado. São eles: o direito à assistência social, o direito ao salário mínimo, o direito ao trabalho, o direito à educação e o direito à saúde.

Esses direitos sociais a que Bobbio (3) definiu como direitos de $2^{\mathrm{a}}$ geração têm a saúde individual e coletiva como direito inerente aos seres humanos, devendo ser garantido a todos sem exceção.

A complexidade do tema acompanha a evolução da sociedade humana desde os tempos antigos, considerando a saúde como valor para qualquer pessoa, independentemente da sua época e da sua coletividade. Nesses últimos tempos, o fenômeno do Direito à Saúde assina as suas bases, as inovações da sociedade atual no âmbito de melhorar a qualidade de vida de seres humanos. Há a necessidade de proteção e defesa da saúde, de ordem pública e interesse social nos termos da lei.

Com dimensões continentais, o Brasil é um país de importante potência econômica, organização política e relação internacional. No rank mundial, se categoriza na linha como o Canadá, Estados Unidos e a China.

A República Federativa do Brasil possui vinte e sete estados. É limitado em suas fronteiras por 10 países vizinhos: Argentina, Colômbia, Peru, Uruguai, Paraguai, Bolívia, Venezuela, Guiana, Guiana Suriname e Guiana Francesa.

Por outro lado, Angola é um país composto de dezoito províncias. Tem nas suas fronteiras 4 países limítrofes: Congo - Brazzaville, República Democrática do Congo (RDC), Zâmbia e Namíbia (África).

O presente estudo tem como objetivo a comparação do direito à saúde na Constituição angolana e brasileira e a articulação do Sistema Único de Saúde - SUS, no 
Brasil e o Sistema Nacional de Assistência Médica, em Angola, identificando-se as semelhanças e diferenças em ambos textos constitucionais.

\section{Metodologia}

Partiu-se da análise documental formada pelo texto normativo-constitucional do Brasil e de Angola, amparada pela literatura afim com o tema da constitucionalização do direito à saúde e a construção dos sistemas de saúde de caráter público.

Para a análise do texto da Constituição brasileira foi feito o download de seu inteiro teor do sítio http://www.planalto.gov.br/ccivil 03/Constituicao/Constituicao.htm e após procedeu-se a identificação e leitura do capítulo correspondente à Ordem Social e a Saúde.

Para a análise do texto da Constituição de Angola, foi feito o download de seu inteiro teor, no sítio www.ambasciatangolana.com/pt/datigeo-e-ind-dem.php.

Após a leitura de ambos os textos, foram extraídos os fragmentos correspondentes à saúde, que após organizados em matrizes, foi possível compará-los

\section{Resultados e Discussão}

A República de Angola é um estado unitário que respeita, na sua organização, os princípios da autonomia dos órgãos do poder local e da desconcentração e descentralização administrativa. ${ }^{2}$

Angola fica localizada a sudoeste do continente africano (figura 1) e tem uma área de $1.246 .700 \mathrm{~km}^{2}$. O país faz fronteira com o Congo, Zâmbia e Namíbia e é banhado pelo Oceano Atlântico em sua porção oeste.

Angola é considerado o segundo maior produtor de petróleo da África Sub Sahariana.

\footnotetext{
${ }^{2}$ Constituição da República de Angola artigo 8ํㅜ
} 
Figura 1 - Localização de Angola

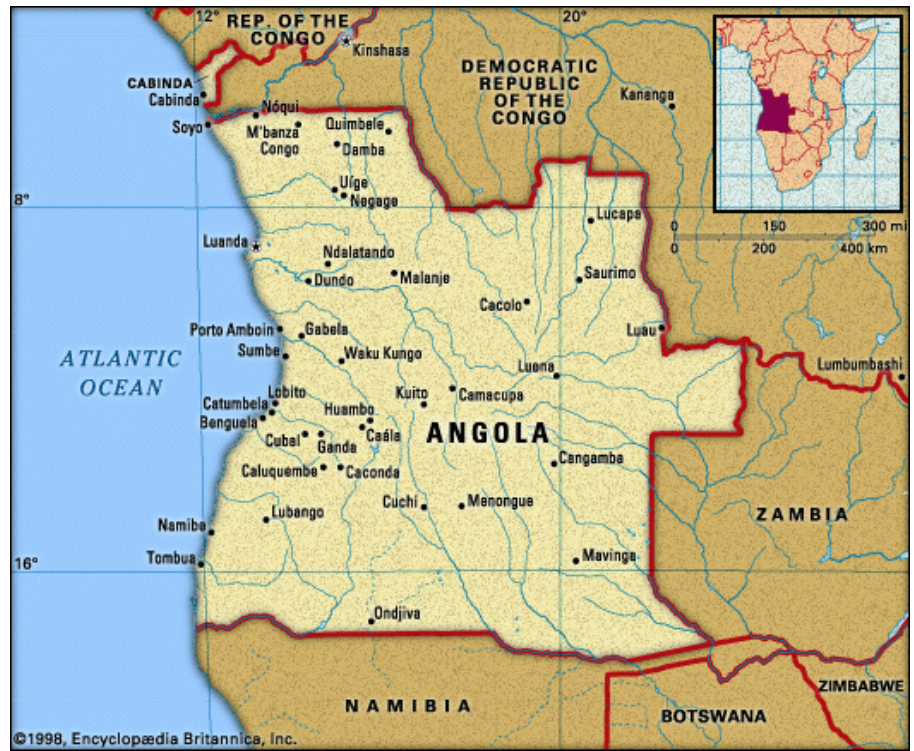

Fonte: http://www.spanport.ucsb.edu/faculty/mcgovern//an

Com uma população de aproximadamente, 17.5 milhões de habitantes distribuídos nos já mencionados $1.246 .700 \mathrm{~km}^{2}$, Angola, capital Luanda, apresenta 18 províncias: Bengo, Bengela, Bié, Cabinda, Cuando Cumbango, Cuanza Norte, Cuanza Sul, Cunene, Humbo, Huila, Luanda, Lunda Norte, lunda sul, Malanje, Moxico, Namibe, Uige, Zaire.

Tornou-se independente de Portugal em 1975 e uma devastadora guerra civil durou até 2002

A história de saúde em Angola confunde-se com a história da exploração da maior riqueza do país: o diamante. A colônia refém dos interesses da Coroa Portuguesa e seus sucessivos governos tinha na companhia Diamong que explorava seus recursos naturais à exaustão, sua única fonte de serviços e ações de saúde.

Segundo Varanda, quando se refere à companhia exploradora de diamantes:

[...]. Neste caso houve um cuidado extremo com a saúde dos trabalhadores e das populações da região. No entanto essa vigilância sanitária encontrava-se intimamente ligada com ideais de produtividade e constante melhoria na gestão dos recursos humanos disponíveis (4)

No início do século XX, a empresa Forminiére descobriu diamantes em territórios contíguos no nordeste de Angola. A Forminiére era uma empresa belga que atuou na 
República Democrática do Congo (RDC), ex-Zaire; país vizinho de Angola. A descoberta de diamante pela Forminiére nas fronteiras dos dois países, fez com que se constituísse uma cooperação de interesses comuns entre a Diamang e a Forminiére.

Em 1912, foi criada a Empresa Pesquisas Mineiras de Angola (PEMA), que posteriormente foi extinta e seu patrimônio e concessão para a exploração dos diamantes foi transferido em 1917, à Diamang, empresa formada de capital português, belga, francês e norte-americano, os direitos de exploração de diamantes em todo território angolano.

O contrato estabelecido com o governo da colônia de Angola tratava com que a companhia detivesse a exploração de diamantes em todo o território. Além disso, na área da sua concessão, detinha o privilégio da exclusividade de toda qualquer atividade comercial. O contrato também obrigava o estado a ajudar no recrutamento de mão-deobra nativa, necessária ao funcionamento da companhia. Por seu turno, a companhia deveria prestar assistência médica, instruir e elevar a moral dos nativos. O Estado recebia, em troca da concessão, $40 \%$ dos lucros da empresa, índice que posteriormente foi elevado para $50 \%$.

O crescimento quase exponencial da produção de diamantes não teve paralelo em outras áreas da Diamang. No serviço de saúde da companhia existia, em 1921, um único médico a serviço daquela empresa. Oito anos mais tarde havia dois médicos, sete enfermeiros europeus e vinte enfermeiros nativos formados pela própria Diamang. Essa formação se passava das aulas práticas com muitos exercícios no campo hospitalar. É claro que ao lado de um médico ou enfermeiro português e a prática na área da saúde se passava dos mais experientes aos alunos. A empresa de diamantes tinha a equipe Médico-Sanitária do Conselho de Chitatu, no Hospital de Dundo. A coordenação na formação dos enfermeiros se baseava na: assistência médica prática no uso do microscópio (hematologia, parasitologia etc), os cuidados da enfermagem, técnica de socorro e administração hospitalar.

Um crescimento mais consistente verificou-se no número de formações ou centro hospitalares e unidades de saúde. Hospitais, maternidade, dispensários-enfermarias, dispensários (para o atendimento ambulatório do paciente), postos sanitários e postos de socorro. Na primeira década de funcionamento da companhia Diamang eram cinco 
as formações existentes: três hospitais, um dispensário e um posto sanitário. Este número subiria para 31 em 1935, atingindo 94 em 1962 e 133 em 1970 com 11 hospitais, oito maternidades, quatro dispensários-enfermarias, dois dispensários, 14 postos sanitários e 94 postos de socorro (6), (7).

O investimento da companhia na saúde era completado por políticas de repovoamento e fixação de populações na sua região. Tais iniciativas eram conduzidas por meio de diversos incentivos como disponibilização de terra e sementes, "ofertas" de contratos de trabalho que incluíam ordenado ao trabalhador e sua família.

A assistência médica prestada pela companhia incluía alguns serviços que variavam de inspeções médicas em minas, vacinações e cuidados pré e pós-natal, até o estabelecimento de campanhas móveis com respectivas consultas, vigilância sanitária e tratamentos nas aldeias visitadas. As ambulâncias percorriam cada setor sanitárioadministrativo mapeando os indivíduos e visitando todas as aldeias existentes. Diversas ações políticas e curativas foram efetuadas, como o recenseamento das populações, persuasão dos doentes a submeterem-se a tratamento (que, no caso da doença do sono, chegava a durar nove meses) e reorientação dos casos mais graves e de grávidas.

Com base em campanhas de profilaxia a Diamang conseguiu penetrar em áreas isoladas que administrativa ou militarmente não conseguiria. Os habitantes da região passaram a estar sob a proteção e influência da companhia, outorgando-Ihe uma maior possibilidade de incorporação na força de trabalho.

Após a segunda Guerra Mundial os ventos da história começaram a mudar. A Inglaterra e o imperialismo perdiam a hegemonia que até então detinham. Inúmeras colônias, por todo o globo, começaram a obter independência, como as do sudoeste asiático nos anos 1940 e 1950 e da África nos anos 1960.

No entanto, o Portugal do Estado-novo mantinha a sua política colonial e utilizava a Diamang e seu serviço de saúde casos exemplares da colonização portuguesa.

$\mathrm{Na}$ data de 4 de fevereiro de 1961, constitui-se a luta armada de libertação nacional e para a independência de Angola. 
Em 1975, 11de novembro é declarada a independência de Angola. E em 1992, o direito à assistência médica e medicamentosa, passou a constar na Constituição do país.

Em 2010, uma nova Constituição foi promulgada no país.

O quadro 1 demonstra os aspectos comparativos entre o texto constitucional de Angola e do Brasil, no que se refere à saúde.

Quadro 1: Quadro comparativo dos aspectos constitucionais da saúde nas cartas políticas do Brasil e de Angola

\begin{tabular}{|c|c|c|}
\hline Temas & $\begin{array}{c}\text { Constituição } \\
\text { Angolana }\end{array}$ & $\begin{array}{c}\text { Constituição } \\
\text { Brasileira }\end{array}$ \\
\hline \multirow{3}{*}{$\begin{array}{l}\text { Diretos e garantias } \\
\text { fundamentais }\end{array}$} & $\begin{array}{l}\text { Art. } 21, \mathrm{~d} \text { : } \\
\text { Promover o bem-estar, a solidariedade } \\
\text { social e a elevação da qualidade de } \\
\text { vida do povo angolano, } \\
\text { designadamente dos grupos } \\
\text { populacionais mais desfavorecidos }\end{array}$ & $\begin{array}{lll}\text { Art.6o-- } & & \\
\text { São direitos } & \text { sociais } & \text { a } \\
\text { educação, a } & \text { saúde, } & \text { o } \\
\text { trabalho }[. . .] & & \end{array}$ \\
\hline & $\begin{array}{l}\text { Art } 21, \mathrm{f} \text { : } \\
\text { Promover políticas que permitam tornar } \\
\text { universais e gratuitos os cuidados } \\
\text { primários de saúde }\end{array}$ & \\
\hline & $\begin{array}{l}\text { Art.21,i: } \\
\text { Efectuar investimentos estratégicos [...] } \\
\text { na educação, na saúde, na economia } \\
\text { primária [...] }\end{array}$ & \\
\hline Direito à saúde & $\begin{array}{l}\text { Art.77 } \\
\text { O Estado promove e garante as } \\
\text { medidas necessárias para assegurar a } \\
\text { todos o direito à assistência médica e } \\
\text { sanitária, bem como o direito à } \\
\text { assistência na infância, na } \\
\text { maternidade, na invalidez, na } \\
\text { deficiência, na velhice em qualquer } \\
\text { situação de incapacidade para o } \\
\text { trabalho [...] }\end{array}$ & $\begin{array}{l}\text { Art. } 196 \\
\text { A saúde é direito de todos e } \\
\text { dever do Estado, garantido } \\
\text { mediante políticas sociais e } \\
\text { econômicas que visem à } \\
\text { redução de doenças e de } \\
\text { outros agravos e ao acesso } \\
\text { universal e igualitário às } \\
\text { ações e serviços para sua } \\
\text { promoção, proteção e } \\
\text { recuperação }\end{array}$ \\
\hline $\begin{array}{l}\text { Dever do Estado } \\
\text { frente à saúde }\end{array}$ & $\begin{array}{l}\text { Art.77, } 2 \\
\text { Para garantir o direito à assistência } \\
\text { médica e sanitária incumbe ao Estado: } \\
\text { a) Desenvolver e assegurar a } \\
\text { funcionalidade de um serviço de saúde } \\
\text { em todo o território nacional; } \\
\text { b) Regular a produção, } \\
\text { distribuição, comercio e o uso dos } \\
\text { produtos químicos, biológicos, }\end{array}$ & $\begin{array}{l}\text { Art. } 196 \\
{[\ldots] \text { dever do Estado, }} \\
\text { garantido mediante políticas } \\
\text { sociais e econômicas[...] } \\
\text { Art. } 198 \\
\text { As ações e serviços públicos } \\
\text { de saúde integram uma rede } \\
\text { regionalizada e hierarquizada } \\
\text { e constituem um sistema }\end{array}$ \\
\hline
\end{tabular}




\begin{tabular}{|c|c|c|}
\hline & $\begin{array}{l}\text { farmacêuticos e outros meios de } \\
\text { tratamento diagnóstico; } \\
\text { c) Incentivar o desenvolvimento do } \\
\text { ensino médico-cirúrgico e da } \\
\text { investigação médica e de saúde. }\end{array}$ & único $[\ldots]$ \\
\hline Relevância Pública & & $\begin{array}{l}\text { Art. } 197 \\
\text { São de relevância pública as } \\
\text { ações e serviços de saúde } \\
\text { cabendo [...] }\end{array}$ \\
\hline $\begin{array}{l}\text { Participação do } \\
\text { setor privado }\end{array}$ & $\begin{array}{l}\text { Art. } 77,3 \\
\text { A iniciativa particular e cooperativa nos } \\
\text { domínios da saúde, previdência e } \\
\text { segurança social é fiscalizada pelo } \\
\text { Estado e exerce-se nas condições } \\
\text { previstas na lei }\end{array}$ & $\begin{array}{l}\text { Art. } 199 \\
\text { A assistência à saúde é livre } \\
\text { à iniciativa privada } \\
\text { Art. } 199, \S 10 \\
\text { As instituições privadas } \\
\text { poderão participar de forma } \\
\text { complementar do sistema } \\
\text { único de saúde [...] }\end{array}$ \\
\hline Controle Social & & $\begin{array}{l}\text { Art. } 198 \\
\text { As ações e serviços públicos } \\
\text { de saúde [...] organizado de } \\
\text { acordo com as seguintes } \\
\text { diretrizes: } \\
\text { I- ... } \\
\text { II - ... _ participação da } \\
\text { III - comunidade } \\
\text { com }\end{array}$ \\
\hline
\end{tabular}

Fonte: texto das Constituições do Brasil e de Angola

No que se refere aos direitos fundamentais, a Constituição de Angola identifica-se bastante com a brasileira. Os elementos garantidores dos mais fundamentais direitos da pessoa humana, obviamente inerente à saúde, estão garantidos em ambos documentos.

A Constituição brasileira elenca já no Título I os princípios fundamentais que norteiam o Estado brasileiro e sua relação com a sociedade. Também a Constituição de Angola em seu Título I transcreve os fundamentos da república.

No Título II, na CF/88 já vem elencado os direitos e deveres individuais e coletivos, o que a Constituição de Angola o faz no Título I Artigo 21.

Os termos usados por ambos documentos sobre os direitos e garantias fundamentais são muito semelhantes, fazendo supor que a carta brasileira serviu de inspiração ao constituinte angolano. 
O direito à saúde é garantido em ambas Constituições. No entanto, o direito à saúde garantido na Constituição brasileira é significativamente de caráter mais ampliado pois, engloba a promoção da saúde, a proteção da saúde e a recuperação da saúde.

No texto angolano, o direito à saúde é o direito à assistência médica e à assistência sanitária. Certamente, quis o legislador constituinte dar um tratamento dicotômico ao direito à saúde. A assistência sanitária pode ser interpretada como as ações e serviços de saúde típicas do Estado e que, muito dificilmente, será prestada pela iniciativa privada.

As ações e serviços de assistência sanitária devem compreender as vigilâncias epidemiológicas de doenças e vetores de doenças e a vigilância sanitária de controle de bens e serviços para saúde.

Ainda a Constituição angolana garante uma proteção à saúde das crianças, dos idosos e dos deficientes. De forma especial o texto constitucional garante assistência à deficiência na velhice. Isto tem grande importância especialmente pelas pessoas que ficaram deficientes em função de ferimentos da longa guerra civil angolana. Ainda hoje, a população mais carente é vítima das granadas enterradas nas superfícies dos terrenos, que ao explodiram, têm ceifado vidas, quando não deixar indivíduos adultos e crianças deformados.

O dever do Estado angolano em função da saúde é de garantir serviços de assistência em todo o território nacional. Como Angola é Estado unitário, os serviços de saúde prestados nas províncias são de obrigação da União, diferente do Brasil, que é um país federativo.

Também é obrigação do Estado angolano o controle e fiscalização de produtos médicos e biológicos para a saúde bem como o controle de doenças.

A Constituição brasileira, além de determinar o dever do Estado, institui a forma como este dever deve ser cumprido, ou seja, pelas políticas sociais e econômicas. A Constituição angolana não faz referência ao modo que o Estado deve cumprir suas obrigações com a saúde.

A Constituição brasileira determinou que ações e serviços de saúde são de relevância pública. A Constituição angolana é silente quanto a este aspecto. 
A Constituição angolana permite a participação privada na saúde, desde que fiscalizada pelo Estado.

A Constituição brasileira permite que somente na área da assistência médica poderá haver a contribuição da iniciativa privada. As instituições privadas poderão participar de forma complementar do Sistema Único de Saúde.

A Constituição angolana não trata do controle social e a participação democrática na saúde. O país ainda não tem sua democracia amadurecida para participar das decisões do Estado sobre a sua saúde.

A Constituição brasileira foi muito generosa com a participação democrática, pois, garantiu ao povo do Brasil, a oportunidade de participar da vida pública e das decisões do Estado.

As conferências de saúde e os conselhos de saúde são os instrumentos que garantem a participação popular.

\section{Considerações finais}

Da análise comparativa dos textos constitucionais, conclui-se que, em matéria de direito à saúde, a sociedade brasileira avançou mais em seu texto constitucional que a angolana. De fato, tal diferença essencial nos textos normativos deve-se a trajetória histórica diametralmente divergente que tomou o povo angolano e brasileiro.

Enquanto a Constituição de 1988 proclama o Direito à Saúde como um direito de todos, não fazendo distinção entre os destinatários da norma, em Angola o texto foca em contingentes da população mais vulneráveis, como crianças e velhos.

Em verdade constatou-se que, no que se refere aos direitos fundamentais, a Constituição de Angola identifica-se bastante com a brasileira. Os elementos garantidores dos mais fundamentais direitos da pessoa humana, obviamente inerente à saúde, estão garantidos em ambos documentos. A saúde é reconhecida como direito do cidadão. O reconhecimento do direito à saúde no Brasil ocorreu por meio de sua inscrição no artigo 196 da Constituição Federal de 1988. Por outro lado, é de mesmo modo a saúde é reconhecida como direito no artigo 77 da Constituição Angolana de 2010. 
Os termos usados por ambos documentos sobre os direitos e garantias fundamentais são muito semelhantes, fazendo supor que a carta brasileira serviu de inspiração ao constituinte angolano. É necessário, ressaltar nesse trabalho que Angola conseguiu a saída depois de 27 anos de guerra civil, também se libertou do conceito constitucional tradicional português. Desse modo, desde 21 de janeiro de 2010, a sua carta magna é mais brasileira que portuguesa.

No texto angolano, o direito à saúde é o direito à assistência médica e à assistência sanitária. Certamente, quis o legislador constituinte dar um tratamento dicotômico ao direito à saúde. A assistência sanitária pode ser interpretada como as ações e serviços de saúde típicas do Estado e que, muito dificilmente, será prestada pela iniciativa privada.

De forma especial o texto constitucional garante assistência à deficiência na velhice. Isto tem grande importância especialmente pelas pessoas que ficaram deficientes em função de ferimentos da longa guerra civil angolana. Ainda hoje, a população mais carente é vítima das granadas enterradas nas superfícies dos terrenos, que ao explodiram, têm ceifado vidas, quando não deixar indivíduos adultos e crianças deformados.

O Dever de Estado frente à saúde. O dever do Estado angolano em função da saúde é de garantir serviços de assistência em todo o território nacional. Como Angola é Estado unitário, os serviços de saúde prestados nas províncias são de obrigação da União, já que, diferente do Brasil, que é um país federativo.

Constatou-se que existem poucas semelhanças e muitas diferenças no contexto constitucional no que se refere à saúde entre a República Federativa do Brasil e a República de Angola. No entanto, é preciso reprisar, são dados afetados especialmente pela realidade histórica diferenciada que cada sociedade separada pelo Atlântico vivenciaram.

É preciso ampliar esforços entre os dirigentes e a vontade popular de cada sociedade. Fazer um trabalho mais intenso utilizando o direito à saúde como ferramenta dentro do contexto constitucional para encontrar novos caminhos multidisciplinares para reconstrução do sistema de saúde. Sempre com a participação e controle da população. 
O atual artigo 77 , da Constituição angolana, não tem soluções que permitam atuação integral na participação do cidadão angolano sobre assunto do direito à saúde e políticas públicas de saúde no sistema nacional de assistência médica. Mas, de outro lado, foi um movimento democrático que vem reconstruindo o país que soube promulgar sua nova Carta Constitucional em 2010. A passos pequenos chegaremos na plena democracia participativa em saúde.

Finalmente, a busca da saúde, será sempre uma preocupação popular em quando a sociedade humana existir, nesse processo tem que seguir as inovações cientificas tecnológicas para que as gerações futuras encontram uma vereda reta com tanta complexidade que oferece o domínio da saúde. Nesse terceiro milênio, tempo da alta tecnologia, mundo do conhecimento. A tomada da consciência será indispensável para bem caminhar com saúde na materialização do direito à saúde, legislação e judicialização nas ações e serviços de saúde.

É claro que nesse tempo da democracia, a humanidade precisa tomar consciência, na organização social pelo intermédio da educação e só assim que teremos pessoas com alta qualidade de vida. A saúde foi, e será sempre considerada como uma res púbica ${ }^{3}$, isso é responsabilidade de todos.

${ }^{3}$ Res pública: O bem comum, um valor que serve a todos. 


\section{Referências}

1 Brasil. Constituição da República Federativa do Brasil de 5 de outubro de 1988. Brasília: Senado Federal, 2013.

2 Angola Constituição da República de Angola de 21 de janeiro de 2010. [Acesso em 22 jul 2013]. Disponível na URL < www.ambasciatangolana.com/pt/datigeo-e-ind-dem.php $>$.

3 Bobbio, N. A Era dos direitos: presente e futuro dos direitos do homem. Rio de Janeiro: Campus, 1992.

4 Varanda, J. A Saúde e a Companhia de Diamantes: História, Ciências, Saúde, 2004 11: 268-68. [Acesso em 12 abr 2013]. Disponível na Internet: < http://www.scielo.br/pdf/hcsm/v11s1/12.pdf $>$.

5 Marques, R; Campos, RF. Relatório sobre os Direitos Humanos: Quando o Crime Brilha. Contexto sócio-geográfico. Lundas: [s.n.] 2004 p.5-70 [ Acesso em 12 jul 2013]. Disponível em http://www.wilsoncenter.org./topics/docs/LPMMarq.pdf>.

6 Ngoyi, L. Anthropologie Médicale: La culture dans La société africaine pour Le changemnete des mentalités. Lubumbashi, 1998[s.n.]

7 Yanka, BN. La Médecine Traditionnelle: Anthropologie Médicale. Le sistème de santé africain. UNILU, 1995.

Recebido em 04/12/2013 Reapresentação em 06/06/2014 Aprovado em 12/11/2015

Como citar este artigo:

Kapalu I. O Direito à Saúde na Constituição angolana e brasileira: um estudo comparado. Revista Cadernos Ibero-Americanos de Direito Sanitário. 2016 jan./mar, 5(1):220-233. 